\title{
Association of risk factors with musculoskeletal disorders among male commercial bus drivers in Malaysia
}

\begin{abstract}
A national study in Malaysia was conducted with the main objective being to determine the prevalence of musculoskeletal disorders (MSDs) and the association between risk factors and MSDs among Malaysian bus drivers. Cross-sectional data were collected from 1,181 male commercial bus drivers in Malaysia using questionnaires to determine demographic, working characteristics and a translated Nordic questionnaire to determine MSD complaints. A Human Vibration Meter was used to measure whole body vibration (WBV) exposure, and postural analysis was used to evaluate awkward working posture. To assess psychological factors, the validated Profile of Mood States (POMS) was used. The overall prevalence of MSD was $81.8 \%$ and, by body parts, low back pain was reported to be the highest complaint of lifetime MSD (58.5\%) compared to other body parts. The levels of WBV acceleration magnitude $A(8)$ exceed the European Union Directive $(0.54 \mathrm{~m} / \mathrm{s} 2$ root-mean-square [r.m.s.] acceleration), and only $1.2 \%$ of the bus drivers adopt more than $40 \%$ of awkward postures while driving. Logistic regression analysis, controlling for age, income, education level, and work activities, revealed that factors such as lack of seat adjustability, uncomfortable seat, seat's material, seat contour and design, WBV exposure, smoking, frequency of daily trips, duration of daily driving, prolonged sitting, working part time, and psychological factors (namely, feeling stress, feeling worried, feeling fatigued) were important risk factors of MSDs among Malaysian bus drivers. As a conclusion, bus drivers are exposed to a combination of risk factors that may lead to an increased risk of developing MSDs.
\end{abstract}

Keyword: Musculoskeletal disorders; Whole body vibration; Posture; Profile of Mood States (POMS); Commercial bus drivers 